\title{
Memória coletiva e insurgência contra o olvido: em favor da convivência na escola
}

Roseli Fischmann*

\section{Resumo}

O artigo busca analisar como o abandono amnésico a que o Estado e a sociedade brasileira têm relegado a memória coletiva pode impactar a convivência escolar, por meio de estudo comparativo, com base em levantamento bibliográfico e documental. Procura discutir o direito à memória como fonte de transformação social, em especial na escola. Pontua a reflexão de Habermas sobre o "Memorial às vítimas da Guerra e da dominação violenta", em Berlim. Analisa temas ligados à discriminação a indígenas e negros no Brasil, bem como dispositivos constitucionais que devem repercutir sobre o fazer escolar, a gestão, e sobre políticas públicas de educação. Tendo como objetivo propiciar alguns meios que auxiliem na definição de políticas públicas de educação, procura sugerir fontes de subsídios, na escola e na sociedade, para a reflexão sobre relevantes processos que têm sido marginalizados da consciência nacional e, contudo, resistem como conteúdos recalcados que retornam quando e onde menos se espera. Palavras-chave: Memória coletiva. Consciência nacional. Memória e políticas públicas. Convivência escolar.

\section{Introdução}

A vida cotidiana na escola, na qual se dá a convivência entre discentes e docentes, tem sido marcada por (o)pressões de diversos tipos, que conduzem, por um lado, ao que tem sido chamado de o mal estar docente e, por outro, a situações de violência, material ou simbólica, que atingem a comunidade escolar como um todo, mas em particular crianças e adolescentes que são as parcelas mais vulneráveis, quando consideradas as populações vulneráveis, ou melhor, vulnerabilizadas pelas condições gerais de vida.

Nas décadas recentes, pesquisas têm trazido alguma luz sobre esses temas tão diversos quanto relacionados, resultando em ações dos órgãos oficiais de diferentes estados e municípios brasileiros, e também do governo federal, como o exemplo

* Doutora em Filosofia e História da Educação, Universidade de São Paulo (USP). E-mail: roseli.fischmann@uol.com.br 
dos temas transversais dos Parâmetros Curriculares Nacionais, em especial Pluralidade Cultural. Semelhantes ações têm sido concentradas em projetos com maior ou menor impacto sobre a situação, algumas vezes envolvendo, mesmo, a relação entre universidade e escola, para o tratamento do tema na prática escolar (como a chamada "Escola da Família" no Estado de São Paulo).

Contudo, há uma vertente que, embora esboçada aqui e ali, ainda está por ser explorada de modo mais profundo e que merece atenção. Trata-se do tema da memória coletiva, tanto a ser abordada e compreendida na escola, como, em particular, dos impactos sobre a escola, pública e privada, que advém do abandono amnésico a que o Estado e a sociedade brasileira têm relegado a memória coletiva nacional, historicamente.

Se a criação da Comissão Nacional da Verdade, em 2012, significou um marco oposto a essa tendência, o esforço de admissão da construção da memória coletiva no espaço social ainda é recente e incipiente frente às necessidades que se têm para que se faça um enfrentamento mais adequado das mazelas de que sofre o País, a escola aí incluída como destino e origem.

Em particular, quando se trata de convivência na escola (ou mesmo fora dela), é indispensável compreender o horizonte mais amplo da situação, assim como a formação de mentalidades que se dá fora da escola e para ela retorna, realimentando práticas e conflitos, recriando divergências e desigualdades. Caberia perguntar, assim, se os diversos modos de violência que a escola vive não teriam ligação com o que foi implantado oficiosa e mesmo institucionalmente nos diversos momentos de autoritarismo que o Brasil viveu, como em particular o mais recente período ditatorial, de 1964 a 1985.

Parece ser plausível afirmar a possibilidade de que tenha se capilarizado pela sociedade a violência que foi praticada (e sofrida por indivíduos, por grupos organizados e pela sociedade) como terrorismo de Estado, durante a ditadura recente, e que assim tenha atingindo o cotidiano de famílias e instituições como prática corriqueira, "legitimada" pelo uso, em que os mais fortes arrogam-se o direito de colocar-se como senhores dos destinos diários dos mais fracos sob o que encaram como sendo seu domínio.

Embora a Escola da Família tenha sido de aplicação e resultados controversos, esse debate excede o escopo desse artigo. 
Ou seja, enquanto a cidadania crítica entregava-se à militância anti-ditadura de formas variadas - no ativismo político ou no cotidiano, de modo armado ou não, sofrendo perseguição diária em pressões várias em todos os ambientes, com vigilância sobre cada conversa ou ação -, travavam-se, em dimensão distante daquela que o Estado ditatorial podia atingir, lutas por sobrevivência da consciência livre e da autonomia individual, sem as quais a reconstrução da democracia não seria possível ${ }^{2}$. Como essa resistência disseminada no cotidiano (ainda que "diluída" sob a aparência de "vida normal"), ou o abandono da memória, ou ainda a busca tardia da verdade apresentam-se como componentes constituintes da aceitação ou do repúdio à violência, em todas as suas formas? Que papel caberia à educação, especialmente à escola, nessa luta pelas consciências? Que políticas públicas as respostas a essas questões poderiam propor?

A referência a vivências internacionais pode auxiliar o desenvolvimento dessa perspectiva que, frente ao olvido na esfera pública, reverberando na esfera privada, busca a reconquista do direito à memória como fonte de transformação social, impactando a formulação de políticas públicas e mesmo o cotidiano escolar e sua gestão. Por isso propõe-se a reflexão de Habermas (2003) sobre a decisão e definição do monumento aos mortos pelo nazismo, em Berlim, a partir de proposta de alemães e não de judeus, lembrando, mais adiante, a reflexão de Celso Lafer como amicus curiae no caso Ellwanger, junto ao Supremo Tribunal Federal.

\section{Arqueologia da reparação: entre heranças e fronteiras}

Em trabalho anterior, mencionava que para Foucault, "a arqueologia [do saber, por ele iniciada] se dirige - ao discurso em seu volume próprio, na qualidade de monumento. (...) Recusa-se a ser alegórica. (FOUCAULT, 1977, p. 159). Se o discurso é monumento, é nele que se processa a investigação arqueológica foucaultiana. É nesse mesmo sentido que Foucault (1977, p. 169) denomina -discurso-objeto o material sobre o qual se debruça e pesquisa." (FISCHMANN, 2013, p. 26).

Ora, se é possível investigar uma arqueologia do saber, não seria possível trabalhar em prol de uma arqueologia da reparação, em busca de compreender o que chega ao momento atual como herança, seja ganho a receber - por quem, de quem -, seja fatura a pagar - por quem, a quem?

Como tratam, por exemplo, resultados de investigação de Adorno (1969, volume utilizado; copyright 1950) e colaboradores, desenvolvidos no final dos anos 1940, logo após o término da Segunda Guerra. 
$\mathrm{Na}$ investigação arqueológica, o que é encontrado passa a ser patrimônio da humanidade, porque referido a um passado do qual pouco se saberia, não fossem os sítios arqueológicos a indicar caminhos e edificações, modos de viver e conviver, assim como de morrer. Por outro lado, como lançando mensagens do passado ao futuro, erguem-se monumentos em honra de pessoas e em memória de fatos vividos coletivamente, os quais, devidamente representados, vêm a auxiliar a compor, ou construir, a identidade coletiva. (HABERMAS, 2003).

Retomando Foucault (FISCHMANN, 2013, p. 26), o filósofo "afirma que a arqueologia deve comparar, trabalhar com interstícios e vazios. A arqueologia (do saber) 一é um emaranhado de interpositividades cujos limites e pontos de cruzamento não podem ser fixados de imediato (FOUCAULT, 1977, p. 183), não tendo efeito unificador, mas multiplicador.Aarqueologia procura identificar também formas específicas de articulação do âmbito discursivo com o não discursivo". (FOUCAULT, 1977, p. 186).

Compondo a reflexão sobre o historicamente comparado, e sobre o discursivo e o não-discursivo em torno de um monumento, Habermas (2003) analisa a proposta de construção de um monumento, em Berlim, aos judeus mortos pelo regime nazista, durante a Segunda Guerra Mundial. Indaga Habermas (2003), com base nos debates que assombraram a população alemã e, ao mesmo tempo conduziram às decisões em torno da obra: seria mesmo o melhor a fazer, considerando toda a situação, dedicar esse monumento exclusivamente aos judeus? Quem daria ao monumento o sentido? Quem o construiria? Quem decidiria?

Observe-se que essas questões deixam ao largo o tema de quão possível seria representar o que foi a Shoah, ou o Holocausto. Como resolver material e esteticamente a representação do indizível?

Para melhor contextualizar o tema e sua relação com questões brasileiras e educacionais, vale lembrar que em 2015 serão celebrados os setenta anos de vitória dos Aliados, incluindo o Brasil, na Segunda Guerra Mundial. Lembre-se, ainda, que a posição brasileira no âmbito da política internacional da guerra oscilou do apoio inicial a Mussolini e Hitler, pela identidade do regime ditatorial de Vargas à política do Eixo, a, na prática, inevitável aliança com os Estados Unidos, pela pressão ocorrida na política interna e externa. No apoio do Brasil a Hitler, pode-se citar, por exemplo, o lamentável episódio de deportação de Olga Benário Prestes ${ }^{3}$. Na transição entre uma posição e outra, a ação notável de Aracy

A deportação de Olga Benário Prestes, esposa de Luiz Carlos Prestes, aprisionada pela ditadura quando 
de Carvalho, esposa de Guimarães Rosa, na ação diplomática que ambos desempenhavam na Alemanha sob o nazismo, salvando vidas de judeus ao conceder a eles visto para o Brasil, de modo destemido, mesmo frente às condições ameaçadoras que enfrentava. ${ }^{4}$

Um dos marcos daquele momento é a data de 27 de janeiro de 1945, quando se deu a libertação de Auschwitz por quatro soldados soviéticos, que ali chegaram singelamente a cavalo. Começava a ter fim o pesadelo mortal para os judeus e outros grupos perseguidos, e a abertura franca de informações sobre a barbárie para o mundo. Auschwitz, dentre os mais de 20.000 campos erigidos pelos nazistas, de concentração ou de extermínio, foi o campo em que morreu maior número de vítimas do nazismo, cerca de 1,2 milhão de judeus, considerando as vítimas que se contaram apenas ali. Somando todos os campos foram assassinados, em escala "industrial" e de modo sistemático, mais de 6 milhões de judeus, além de incontáveis pertencentes a outros grupos, distribuídos em centenas ou dezenas de milhares de romas (ciganos), negros, homossexuais, portadores de deficiências, opositores ao regime e outros considerados pelos nazistas como sendo sub-humanos, indignos de viver e, desse modo, tratados como se fossem descartáveis. (ARENDT, 1999).

Ou seja, a ideologia e a máquina oficial nazista, mais que autorizar, ordenava que essas pessoas fossem transformadas em vítimas (KELMAN, 1973), de modo que a sua execução, por ser oficialmente sancionada pelo poder vigente, era tratada como se fosse impessoal, como se não dependesse de cada gesto que provocou, de morte em morte, a perda de milhões de vidas humanas ${ }^{5}$. No lado dos algozes, essa impessoalidade recebia o manto de que estariam "apenas cumprindo ordens". No lado das vítimas, $\mathrm{o}$ ataque à dignidade pela desumanização precedia o extermínio.

Mais recentemente, Giorgio Agamben (2008) desenvolve o conceito de "homo sacer" assim denominando o que pode ser morto, que jamais será considerado "sacrificado" ou vítima, porque, por um entendimento coletivo oficial ou oficiosamente autorizado, está liberado seu assassinato, sem restrições. Publicou, entre outras obras, "O que resta de Auschwitz?", tendo como base documentos e obras de sobreviventes, como Primo Levi, ele próprio testemunha da libertação daquele campo de extermínio. Agamben (2008) alerta que o leitor talvez se queixe de encontrar apenas um perpétuo comentário ou o mero testemunho dos sobreviventes, repassado naquele livro. Mas

grávida, representou sua condenação à morte, pois foi do Brasil diretamente para um campo nazista de extermínio. O dramático episódio, de ampla repercussão mundial à época, resultou em livro de Fernando Morais (1985), posteriormente adaptado para o cinema, com direção de Jayme Monjardim em 2004.

$4 \quad$ Ver a esse respeito Schpun (2011).

5 Por extrapolar o foco deste estudo, deixa de ser aqui abordado o tema das inúmeras e diversas omissões de parte de agentes do campo internacional, pois exigiria análise mais detalhada. 
é ali que ele busca novos elementos de compreensão nos paradoxos e aporias. Cita o apotegma de Elie Wiesel sobre o sentimento de culpa do sobrevivente: "Vivo, portanto sou culpado (...). Estou aqui porque um amigo, um companheiro, um desconhecido morreu no meu lugar". (AGAMBEN, 2008, p. 95).

Há sobreviventes do Holocausto a dar testemunho do horror, rememorando o que viveram e como quase morreram. Há sobreviventes que vivem no Brasil, a quem mais recentemente têm sido rendidas justas homenagens, e houve outros que puderam ter aqui descendentes, ainda que tenham lá perecido. Por isso se pode dizer que há sobreviventes diretos, como também os que são, por assim dizer, indiretos. Há os que sobreviveram, porque foram libertados dos campos à beira da morte. Sobreviveram também os que conseguiram refugiar-se no continente americano, ainda que antes chegassem a experimentar a ocupação nazista, estrela amarela no peito, ou o triângulo rosa e demais símbolos criados para expor o que a política do Estado nazista decidiu que passaria a ser estigma e condenação à solução final.

Cada um que sobreviveu traz consigo marcas. Os descendentes, a de sobreviventes indiretos - sequer existiriam, por ser, então, esse o plano: a extinção sistemática e planejada dos judeus e de todos os que fossem considerados como não merecedores de viver.

Besançon (2005) considera que há uma unicidade da Shoah, incomparável a outras formas de totalitarismo brutais, vividas no mesmo Século XX. Contudo, essa unicidade parece fadada a pairar como risco constante de eleição deste ou daquele grupo humano, a cada vez, por não ter sido suficientemente analisado aquele horror inominável, nem transformado em fonte de compreensão para que não mais se repita. A ponto, por exemplo, de ainda existir quem tente negar sua existência histórica, como será tratado na seção seguinte.

Compreendendo ou não, detendo-se na análise ou não, pode-se dizer que, atualmente, cada um da humanidade pode dizer o mesmo que Elie Wiesel - estamos vivos, afinal, porque outros morreram em nosso lugar, ou de nossos pais, de nossos avós. Porque um grupo humano foi escolhido ali como se não fosse merecedor de viver, de habitar o planeta; mas poderia ter sido outro, qualquer outro, uma vez que nada justifica a lógica mortal e sistemática do genocídio cometido ${ }^{6}$.

6 Nesse sentido, o livro de Arendt (1999) traz contribuição inestimável à compreensão, em especial em suas páginas finais, relativas aos termos da sentença de condenação de Eichmann (e não à sentença em si), comparando a que foi escrita e a que, ao ver da filósofa, deveria ter sido escrita. 
Ou seja, nem mesmo monumentos e museus erguidos em memória da Shoah, em diferentes locais do mundo, poderiam dar conta desse processo de desumanização que atingiu, de modos distintos, as vítimas fatais e mesmo seus algozes - mas que a ambos atingiu, como analisa Kelman (1973).

No caso da Alemanha, a decisão de erigir um monumento às vítimas do regime nazista, ou especificamente às vítimas do Holocausto, pode ser considerada uma situação-limite. Indica, assim, como é possível a um Estado fazer, em dado momento, a re-flexão sobre as ações que praticou em outro momento. Essa possibilidade se dá, sobretudo, ao considerar que historicamente há diferentes composições do pensamento do povo, em diferentes momentos, assim como diferentes responsáveis pela governança do Estado, ao longo da história.

Por isso a discussão que Habermas (2003) faz sobre a construção do monumento aos judeus assassinados na Europa podem contribuir para a melhor compreensão da relevância dos debates, ainda que tardios, sobre toda a violência que a ditadura praticou e semeou na sociedade brasileira e, de modo especial, das marcas que deixou, impunemente, no Estado, de tal modo que, ainda na atualidade, pode se encontrar as repercussões e seguidores das piores práticas, como a tortura. Auxilia também, para refletir sobre essa mesma violência e porque tem sido tão difícil avançar apurações e elaborar reflexões públicas.

Habermas trouxe sua análise antes da decisão do Parlamento alemão de erigi-lo, do desenvolvimento do projeto e de sua efetiva construção - sendo relevante lembrar, aqui, que atualmente o monumento já foi construído em Berlim, sendo ponto referencial na cidade. No texto significativamente intitulado "De dedo em riste", Habermas (2003) desenvolve questões sobre: o sentido do monumento, quem deve erigi-lo, sua finalidade e seus destinatários, sua forma, exigências envolvidas e a quem dedicá-lo.

A direção e o sentido destacam-se na análise: trata-se de um monumento contra. Ao contrário dos monumentos que procuram destacar e louvar feitos e pessoas, esse monumento volta-se contra o crime e os criminosos (HABERMAS, 2003), por isso se trata de uma situação-limite. Quem propõe o monumento não são os herdeiros das vítimas ou dos sobreviventes para homenageá-los, como ocorreu em tantas outras partes do mundo. Mas são os herdeiros dos perpetradores do genocídio que propõem uma representação material da violência cruenta e fatal cometida. 
Houve pensadores alemães que questionaram: "não se pode erguer um monumento à própria vergonha" (HABERMAS, 2003, p. 70). Ou, em outras palavras: "não se pode erguer um monumento à própria infâmia" (HABERMAS, 2003, p. 80)7 .

Lembra Habermas que o conjunto das catástrofes do século XX - ao que é possível acrescentar as do início do século XXI - "colocou em xeque quase todas as tradições nacionais" (HABERMAS, 2003, p. 62). De todos os debates provindos de escândalos e traumas, Habermas destaca que uma pergunta crescentemente virulenta colocou-se como única, com força para formar e mudar mentalidades. Em suas palavras (HABERMAS, 2003, p. 63):

Será que nós, que somos cidadãos da República Federal da Alemanha e que herdamos política, jurídica e culturalmente o Estado e a sociedade da 'geração dos réus', somos historicamente responsáveis pelas consequências de suas ações? Será que transformamos explicitamente a recordação autocrítica de Auschwitz num dos componentes de nossa autocompreensão política? Será que aceitamos como elemento de uma identidade nacional rompida a responsabilidade política inquietadora que advém aos descendentes pelo fato de os alemães terem praticado, apoiado ou tolerado uma ruptura na civilização?.

O particular interesse, que esse monumento desperta, além da proposta e do debate sobre sua construção ter ocorrido após a reunificação da Alemanha ${ }^{8}$, guarda ligação com sua vocação a provocar a reflexividade, com o que contribui para operar uma mudança de consciência, afetando o político e o social, ao opor-se ao sentido automático e automatizado que em geral está presente nos monumentos, assim também se contrapondo "à incorporação e à atualização ritualizadora de um evento de significado existencial” (HABERMAS, 2003, p. 80).

Entendendo o monumento como uma ponte entre o passado e o futuro, ainda que não estivesse claro qual geração seria responsável por lançá-la (HABERMAS, 2003 , p. 66), destaca-se com clareza a autoria do monumento e a ética que se pretende alcançar:

Habermas refere-se, de modo especial, a Hermann Lübbe, Rudolf Augstein e Martin Walser, este último a quem Habermas atribui a segunda frase mencionada (HABERMAS, 2003 p. 70 e 80).

8 Vale lembrar que a reunificação da Alemanha, tendo como marco simbólico a Queda do Muro de Berlim, é em si fato relevante, que se apresenta historicamente como um dos sinalizadores do fim da bipolaridade na política internacional. 
A partir do momento em que os descendentes alemães dos réus erigem um monumento às vítimas judias, não se pode mais manter a perspectiva etnocêntrica que até hoje orientou a conscientização auto-referencial acerca da própria origem histórica.

Habermas (2003) afirma que, do mesmo modo, em sua análise, o monumento não poderia dirigir-se exclusivamente ao judeus, pois a escolha de um grupo significaria não apenas o lugar especial desempenhado por esse dado grupo, na relação com aquela Alemanha e aqueles alemães - relevância especial que foi atribuída aos judeus, como afirma Habermas (2003, p. 73). Mas que seria também, e de modo decisivo, mais uma hierarquização entre os seres humanos que foram vitimados durante aquela ruptura com a civilização, escalonados durante a Segunda Guerra, mas todos seguindo o mesmo destino mortal. Semelhante hierarquização e esquecimento significaria algo como executá-los uma segunda vez ou expô-los, e a seus descendentes, à vergonha do abandono no reconhecimento de que sofreram um crime. A exortação de Habermas foi ouvida, e o monumento veio a ser denominado "Memorial às Vítimas da Guerra e da Dominação Violenta”.

Mas aqueles que defendiam que o monumento não fosse construído seriam movidos por uma questão ligada a "os olhares embaraçosos dos outros"? (HABERMAS, 2003, p. 80). Absolutamente não. O que está em jogo é a autocompreensão e autoconsciência que propiciam lidar com a ideia de "uma inclusão que ultrapassa fronteiras" (HABERMAS, 2003, p. 80), para incluir outros e outras fora da usual e desejada referência a um passado monumental - e falso:

Trata-se de alargar o olhar que a cultura dos monumentos de guerra até agora dirigiu ao destino doloroso dos próprios mortos: doravante ela deve incluir também as vítimas que as ações e omissões dos próprios pais e avós transformaram em estrangeiros encerrados num gueto, humilhados e mortos". (HABERMAS, 2003, p. 80).

Haveria um caráter educativo nesse monumento, em Berlim? Nos muitos debates e análises, reiterou-se por diversas vezes que a discussão pública, travada de modo aberto por anos, com seriedade e circunspecção, ácida e sem concessões, teria sido, em si, tão ou mais relevante e teria atingido tão ou mais plenamente o sentido que a própria obra, afetando a autoconsciência dos alemães, como povo. Mesmo 
assim, ao monumento reservou-se um papel educativo no plano da sociedade, que extrapola o que outras agências sociais, inclusive a escola poderiam oferecer-e, mais ainda, que podem de suas repercussões se beneficiarem:

$\mathrm{O}($ (..) projeto de construção de um monumento em Berlim para recordar os mortos revela que a memória cultural de uma nação de cidadãos não se desenvolve apenas através do medium discursivo do ensino, da tradição literária ou da pedagogia dos museus ou locais comemorativos; tudo indica que ela exige, além disso, uma representação e uma ritualização simbólica. (HABERMAS, 2003, p. 98).

A partir desse marco reflexivo, este artigo passa agora a analisar, ainda que brevemente, as bases político-culturais de casos ligados ao Brasil e à escola brasileira para verificar se há como identificar o olvido da memória histórica nacional como base de uma vivência escolar que demora a estabelecer-se de fato como convivência.

\section{Pluralidade e consciência histórica: do olvido nacional à conquista do território escolar}

O objetivo de compartilhar o debate sobre o monumento aos judeus assassinados na Europa, de Berlim, foi o de propiciar um exemplo de debate mais árduo e mais complexo do que aquele que se travou e ainda se trava no Brasil com relação à criação da Comissão Nacional da Verdade, em 2012. De fato, a criação dessa Comissão representou uma conquista, ainda que tardia, de todos e todas que entendem que é preciso trazer o passado à luz para melhor viver o presente e melhor vislumbrar o futuro. A exemplo das discussões na Alemanha sobre o citado monumento de Berlim, as ácidas discussões travadas no Brasil sobre a Comissão, antes de sua criação e já durante sua atuação, são em si educativas, no que se refere a explicitar e ajudar a compreender a dificuldade que se tem no Brasil para encarar o passado, extraindo, então, os fatos que subsidiam a construção e a compreensão da história9 .

Outro exemplo da política de olvido foi a implosão do Carandiru em dezembro de 2002 e a construção de um parque no local, em vez de se garantir a manutenção do espaço para que pudesse rememorar o que ficou conhecido como "o massacre do Carandiru", ocorrido dez anos antes, em outubro de 1992, durante o qual foram brutalmente assassinados 111 presidiários do Pavilhão Nove, da Casa de Detenção, pela ação da Polícia Militar do Estado de São Paulo. Ver a esse respeito "Ascensão e queda do Carandiru: da primeira pedra ao massacre" in O Estado de São Paulo (2011). http://blogs.estadao.com.br/arquivo/2011/05/13/ ascensao-e-queda-do-carandiru-da-primeira-pedra-a-implosao/ . 
É exemplar também do olvido nacional, aquele que se lança por sobre as vítimas advindas das políticas coloniais e das políticas de dominação, no âmbito do Brasil já como país livre a partir de 1822. Semelhante olvido infiltrou-se historicamente na escola, fosse por meio da política de livros didáticos comprometidos com o esquecimento e a omissão, fosse por meio de (falta de) políticas de formação de professores e professoras ${ }^{10}$.

A questão indígena, por um lado, para tentar denominar de modo amplo e abrangente algo complexo e inapreensível em poucas palavras, é alvo sistemático de má compreensão e mesmo de ignorância. Poucos são os que sabem, ainda, que há cerca de 250 grupos indígenas no País, falando mais de 180 línguas, em uma riqueza linguística incomparável e distante da propalada "língua única" que seria o português. O preconceito com que se analisa temas como demarcação de terras, além de outros direitos já conquistados pelos indígenas há tempos, envolvendo identidades dos grupos indígenas e, não raro, sua autonomia, são desprezados e tratados como estranhos (quando não, deletérios) ao conjunto da cidadania brasileira.

O lamentável episódio envolvendo jovens filhos de autoridades em Brasília, no qual foi queimado o índio Galdino, enquanto dormia, é exemplo dessa barbárie que persiste, sonegando informação e formação às crianças e jovens, que poderiam dirigir-se a todos e todas da cidadania de modo digno e igualitário, em vez de encontrarem supostas desculpas para comportamentos criminosos, como fizeram aqueles jovens, que não sofreram as consequências de seu ato, agravado por seu comentário supostamente voltado a pedido de perdão póstumo a Galdino: "Pensamos que fosse um mendigo".

A desumanização assim exposta claramente, além de indicar que funciona de modo precário a imagem popular da proteção de organismos internacionais aos indígenas, envolve também esse tipo de hierarquização formal, burocrática, entre seres humanos, que não guarda relação com respeito aos direitos e reconhecimento da humanidade dessas pessoas, indígenas e mendigos, vítimas de um sistema que aniquila o ser humano ou pouco a pouco, ou em uma golfada.

Mesmo a Lei $\mathrm{n}^{\circ} 11.645 / 08$, que estabelece a obrigatoriedade, em todas as escolas do Brasil, em todos os níveis, da temática História e Cultura Afro-brasileira

10 Esse momento em que se realizam conferências preparatórias para a CONAE - Conferência Nacional de Educação, a ocorrer em 2014, é especialmente oportuno para pensar como incluir nas políticas de formação de professores e professoras temas ligados à memória coletiva, articulando-os com a convivência cotidiana na escola e conteúdos não apenas cognitivos, mas em especial atitudinais. 
e Indígena, ainda encontra resistência e falta de adequação da formação de professores e professoras para que possam cumprir essa obrigatoriedade no exercício de suas funções. Contudo, qual a abordagem que se dá ao genocídio que sofreram os indígenas, quando da colonização portuguesa em terras brasileiras?

Com relação à população negra, ou afro-descendente, a Lei $n^{0}$ 10.639/03 trouxe o atendimento de reivindicação antiga, relativa à inclusão da temática História e Cultura Afro-Brasileira, por muito tempo invocado pelos movimentos negros como recurso determinante na luta contra o racismo.

Entre as muitas possibilidades de análise que o tema do racismo propicia, mas que extrapolam o âmbito de um simples artigo, tomemos apenas dois exemplos, deixando a tarefa de esclarecimento aos bons e complexos artigos e livros já produzidos por pesquisadores e pesquisadoras, em especial negros e negras.

O primeiro refere-se a um quadro comparativo entre negros e não-negros relativo à permanência na escola, produzido pelo IPEA, em pesquisa desenvolvida por Ricardo Henriques (2001). Já muito divulgado, esse quadro que corresponde a um período de 50 anos, demonstra de modo inegável como a escolarização da população negra deu-se em uma curva paralela, diversos pontos abaixo da população não-negra, mantendo-se nesse ponto inferior de modo sistemática e paralelamente simétrico e distante, ao longo das cinco décadas, ou meio século, estudadas.

Ou seja, quando houve melhoria no nível de escolarização da população não-negra, a população negra acompanhou a melhoria, porém mantendo-se equidistante em muitos pontos dos ganhos escolares dos não-negros. Não se registrou, em nenhum momento desse longo período, qualquer alteração da curva da escolarização dos negros que indicasse qualquer sinal de aproximação, progressiva ou em salto, às aquisições escolares dos não-negros, que a tirasse desse paralelo de linhas que pareciam rumar para o ponto de jamais se encontrarem.

Mesmo frente à inegável evidência, os opositores das políticas afirmativas muitas vezes continuaram alegando que tudo se resumia à capacidade de desempenho, e não a um sistema socioeconômico que, antes e durante o tempo escolar, condicionou o acesso, o rendimento e a própria permanência na escola. ${ }^{11}$

11 Ver, por exemplo, FISCHMANN, (2005). 
O segundo refere-se à conquista dos movimentos sociais, em especial dos movimentos negros, que representou a adoção, na Constituição Federal de 1988, em seu Art. 50, XLII, do racismo como crime inafiançável e imprescritível. Contudo, quando se pergunta quantos já foram condenados por racismo, escasseiam os exemplos. Mas há um exemplo, o primeiro caso de condenação por racismo, julgado pelo Supremo Tribunal Federal, que teve profundo caráter educativo. Trata-se do "Caso Ellwanger", como ficou conhecido, relativo ao editor Siegfried Ellwanger, da editora Revisão, de livros que negam o Holocausto.

Após condenação nas sucessivas cortes, iniciando em 1990, com a condenação no Rio Grande do Sul, referendada depois pelo Superior Tribunal de Justiça, ao chegar ao STF trouxe a possibilidade de um debate de largo alcance para o caso brasileiro. A defesa do editor tentou alegar que não poderia ser responsabilizado por racismo, mas por um delito "contra os judeus, contra o judaísmo, contra a comunidade judaica". Buscava, assim, evitar que o crime fosse considerado imprescritível.

É importante ressaltar que a vitória da Justiça deu-se com folga, por oito votos a três, tendo votado contra a concessão de hábeas corpus, portanto pela condenação do editor, os ministros Maurício Corrêa, Celso de Mello, Gilmar Mendes, Carlos Velloso, Nelson Jobim, Ellen Gracie, Antônio Cézar Peluso e Sepúlveda Pertence, pela ordem em que pronunciaram seus votos.

Tratando-se de caso histórico, pareceres de juristas do porte de Miguel Reale Júnior e Celso Lafer subsidiaram os trabalhos, assim como ensaios de acadêmicos do campo da antropologia e da linguística, além de religiosos e líderes comunitários e de movimentos sociais. A dedicação dos magistrados à análise dos pareceres demonstrou que o avanço científico tem papel insubstituível na busca da verdade, em prol da justiça, como se observa na publicação organizada por Maurício Corrêa (2002), reunindo os votos proferidos no julgamento.

Ou seja, para além da indignação ao deparar com inverdades afirmadas como se fossem fatos históricos para pregar o racismo e o ódio contra grupos humanos, a manifestação do magistrado precisou e valeu-se do embasamento que a construção científica do conhecimento tem a oferecer.

O julgamento mostrou também os limites das alegações em prol da liberdade de expressão. Artigo do eminente jurista Tercio Sampaio Ferraz Jr. (2002), compara 
ciência e retórica. Lembra que "quem faz ciência sujeita-se ao julgamento da verdade e do erro". Contudo "quem faz retórica não pode eximir-se da responsabilidade por suas intenções e mesmo pelas consequências até criminosas de suas opiniões".

Para os fins buscados neste artigo, vale lembrar que em parecer do jurista Celso Lafer como amicus curiae, a questão do direito dos mortos à memória $\mathrm{e}$ à dignidade foi invocado em meio a outras reflexões e argumentos relevantes, lecionando sobre o porquê de ser o racismo um crime imprescritível, na Constituição Federal de 1988:

Existe um nexo estreito entre a imprescritibilidade, esse tempo jurídico que se escoa sem encontrar termo, e a memória, apelo do passado à disposição dos vivos, triunfo da lembrança sobre o esquecimento, como explica Alain "Laquièze (Le Debat de 1964 sur l'imprescriptibilité des crimes contre l'humanité, in Droits, 31, 2000, p. 19). (LAFER, 2004, p. 89).

Continua, ainda, Lafer ampliando a análise e trazendo o tema da memória, apropriadamente, porém, aquela que existe sem compartilhamento, sem a busca de reconciliação entre o passado, o presente e o futuro, que é memória de injustiça que a vítima carrega, sem que o perpetrador, ou seus herdeiros, a escute:

A memória das práticas racistas que dificultaram, na História do Brasil, a criação de uma sociedade fraterna, pluralista e sem preconceitos - valores supremos do País consagrados no Preâmbulo da Constituição - é o que o Constituinte quis preservar, para impedir sua reincidência. Por isso conferiu, no art. $5^{\circ}$, LXII, ao crime da prática do racismo o peso e a gravidade da imprescritibilidade. (LAFER, 2004, p. 89).

As medidas mencionadas, relativas à conquista do espaço da escola nas temáticas tratadas, assim como as políticas afirmativas para ingresso no ensino superior, que segue em pleno processo de aplicação nos diferentes estados do Brasil, indicam a morosidade com que o País lida com populações inteiras historicamente excluídas de oportunidades as mais diversas, expostas a riscos, vulnerabilizadas em escala das macropolíticas e das micropolíticas também, no cotidiano abrasivo e devastador a que viveram - e ainda vivem - a maioria das crianças e jovens indígenas, assim como crianças e jovens negras e negros. 
Como é o caso também das escolas de fronteira, nas quais se pratica o bilinguismo e, frequentemente, o multilinguismo, pela presença de crianças dos países vizinhos que falam castelhano e, muitas vezes de grupos indígenas que falam o guarani, ou outras línguas indígenas, o que leva os estudantes dessas escolas, assim como docentes, a falarem o conjunto das línguas pela convivência, ainda que não formalmente ensinadas. As mencionadas escolas são, em geral, alvo de total desconhecimento de professores, professoras e mesmo pesquisadores de outras regiões, como nas grandes metrópoles, que se esquecem que o País tem limites e fronteiras por meio das quais se relaciona com países vizinhos, ficando muitas vezes a escola em meio a um exercício informal de relações internacionais.

Qual a lembrança que há desses grupos? Como, por exemplo, são tratadas populações ribeirinhas na Amazônia, para citar apenas um dos grupos humanos que constroem o cotidiano de regiões brasileiras, em termos culturais, sociais e econômicos, distribuídos pela dimensão continental do Brasil, e que são lembrados, quando muito, em algum noticiário especial de televisão, devidamente glamourizadas e frequentemente "infantilizadas", como se fossem "puras" ou mesmo "ingênuas", mas de todo modo expropriadas de sua humanidade e dignidade.

A violência histórica do Estado contra indígenas e afro-descendentes foi alvo de omissão nos conteúdos ditados por políticas escolares. Mais ainda, a omissão no reconhecimento de sua contribuição na construção histórica do País, em termos culturais, sociais e econômicos, além de significar a sonegação de informações aos estudantes dos mais distintos níveis, privando-os de uma formação cidadã adequada, criou um estímulo adicional cumulativo ao preconceito e à discriminação praticada de modo amplo e impune na sociedade e nos órgãos do Estado, em um processo em que a escola sofria os efeitos de uma sociedade racista e discriminadora, ao mesmo tempo em que a alimentava.

Por isso, o processo de plena inclusão da voz e presença dos diferentes grupos discriminados ainda está se fazendo pelas escolas e pela sociedade, contabilizando conquistas e, ainda, frustrações ${ }^{12}$.

Nesse contexto, não é de se estranhar que tenha sido tão difícil e que ainda gere tantas resistências o estabelecimento e os trabalhos da Comissão Nacional da Verdade.

12 Ver, por exemplo, Araújo, S. (2002), Araújo, R. (2004), Carneiro (2005), Graúna (2013), Molina (2011), Munduruku (2012) e Pereira (2012). 
A possibilidade do desvelamento de brutais violações de direitos humanos, seja pela visibilização da tortura que foi praticada de modo generalizado nos porões do poder ditatorial e ainda resiste em órgãos policiais pelo Brasil, seja pela prática histórica de racismo e genocídio contra indígenas e afro-descendentes, das mais variadas formas, ou ainda pela denúncia da presença marcante da violência contra a mulher - tudo desafia a auto-imagem construída de uma democracia racial, solidária e fraterna, que a todos acolhe. A propósito, a solidariedade é um dos fundamentos do Estado Democrático de Direito, como estabelecido na Constituição Federal de 1988, assim como é um dos seus objetivos o combate ao racismo.

Se é verdade que por algum ponto é preciso iniciar a análise do passado, a criação tardia e ainda tomada como polemica da Comissão Nacional da Verdade é um início, ainda que longe de atender a todo o debate que se precisa fazer no Brasil sobre as perdas e danos sofridos por populações as mais diversas, dilapidando o patrimônio humano e cultural que verdadeiramente forma este País. Cabe perguntar: como levar os processos e resultados da Comissão Nacional da Verdade às salas de aula e, antes, ao conhecimento dos professores e professoras, independentemente de disciplinas de formação e das áreas e temas a que se dediquem?

Observe-se que Habermas, ao discutir o tema de quanto o monumento é centrado nas vítimas ou nos criminosos, lembra que há caso semelhante nos Estados Unidos:

O mesmo acontece com o monumento aos mortos do Vietnã, em Washington, que não é triunfante, pois agora o olhar público tem que se dirigir a vítimas que foram transformadas em estranhos, em inimigos, humilhadas e aniquiladas como sub-humanas, como pessoas que não deveriam mais ser pessoas, através das ações e das omissões dos próprios pais e avós. E essa passagem autocrítica de fronteiras é exigida de uma nação que, devido a um compreensível embaraço, tem, além disso, má consciência com relação aos próprios mortos, mais ou menos 'privatizados'. Por isso, o sentimento de culpa dos sobreviventes em relação aos irmãos que desapareceram durante a guerra foi um motivo importante que sempre implícito nos debates autocríticos da República Federal da Alemanha. (HABERMAS, 2003, p. 71).

Como mencionado anteriormente, o sobrevivente sente culpa, o que pode ser mobilizador da reflexão que transforma a consciência. Mas se o sentimento 
de culpa não encontra lugar, em uma sociedade que a tudo desculpa, simplesmente, como a Lei de Anistia, no Brasil, em 1979, ou antes, com a Lei Áurea, em 1888, ou a ausência de qualquer lei que garantisse direitos básicos aos indígenas desde as viagens lusitanas de conquista, constrói-se uma sociedade sem memória, sem vínculo público de responsabilidade intergeracional, tudo devidamente privatizado ao nível individual, toda dor e perda ou todo suposto ganho, porque se a coletividade não se beneficia, não há ganho que perdure ou que o seja de modo pleno.

Em uma sociedade como essa, ainda estranha-se que a convivência escolar seja marcada por violência material e simbólica. Mas se nada acontece no campo público quando ocorrem violações, como se pode esperar que as bases da convivência no cotidiano escolar sejam plenamente respeitosas? Toda educação tem no exemplo um componente indispensável e no caso do comportamento ético, modelos adultos em que se espelhar são fundamentais para crianças e adolescentes (HORKHEIMER; ADORNO, 1973). Enquanto a sociedade e o Estado não assumirem plenamente seu papel de compreender a violência do passado, talvez melhor proposto no plural pela diversidade das vítimas sacrificadas, será difícil à escola e a seus profissionais vencerem a luta contra uma disposição psicológica ao trato mútuo, na convivência, fazer-se de modo violento. Alimentada pela mentalidade cultural e pelo olvido, pela política e pela economia, semelhante disposição só fará recrudescer.

\section{Referências}

ADORNO, T. W. et al. The authoritarian personality. New York: The Norton Library, 1969. (Studies in prejudice).

ADORNO, T.W. Educação e emancipação. São Paulo: Paz \& Terra, 1995. AGAMBEN, G. O que resta de Auschwitz: o arquivo e a testemunha (Homo Sacer III). São Paulo: Boitempo, 2008.

ARAÚJO, R. Iê, Viva Meu Mestre: a Capoeira Angola da escola pastiniana como práxis educativa. 2004. 152 f. Tese (Doutorado)-Faculdade de Educação da Universidade de São Paulo, Universidade de São Paulo, São Paulo, 2004. 
ARAÚJO, S. Cultura e Escolas-de-Fazenda: elementos para uma reflexão. 2002. 143 f. Tese (Doutorado)-Faculdade de Educação da Universidade de São Paulo, Universidade de São Paulo, São Paulo, 2002.

ARENDT, H. Eichmann em Jerusalém: um relato sobre a banalidade do mal. São Paulo: Companhia das Letras, 1999.

BESANÇON, A. Le malheur du siècle: Comunisme - Nazisme - Shoah. Paris: Perrin, 2005.

CARNEIRO, S. A construção do outro como não-ser como fundamento do ser. 2005. 167 f. Tese (Doutorado)- Faculdade de Educação da Universidade de São Paulo, Universidade de São Paulo, São Paulo, 2005.

FISCHMANN, R. Anotações para uma arqueologia de processos de publicação científica: o caso da editora Mandruvá-Cemoroc. International Studies on Law and Education, [S.1.], n. 13/14, jan./ago., p. 23-31, 2013.

FISCHMANN, R. Historical and legal remarks on cultural diversity and higher education in Brazil in the context of the school system. Higher Education Policy: The Quarterly Journal of the International Assocation of Universities (IAU), v. 18, p. 375-395, 2005.

FOUCAULT, Vigiar e Punir. Petrópolis: Vozes, 1977.

GRAÚNA, G. Contrapontos da literatura indígena contemporânea no Brasil. Belo Horizonte: Mazza, 2013.

HABERMAS, J. Era das transições. Rio de Janeiro: Tempo Brasileiro, 2003.

HENRIQUES, R. Desigualdade racial no Brasil: evolução das condições de vida na década de 90. Rio de Janeiro: IPEA, 2001. (Texto para Discussão 807). Disponível em: <http://www.ipea.gov.br/portal/images/stories/PDFs/ TDs/td_0807.pdf $>$. Acesso em: 30 jul. 2013.

HORKHEIMER, M.; ADORNO, T.W (Org.). Temas básicos da sociologia. São Paulo: Cultrix; EDUSP, 1973. 
KELMAN, H. I.; KELMAN, H. C. Violence without moral restraint: reflections on the dehumanization of victims and victimizers. Journal of Social Issues, [S.1.], v. 29, n. 4, p. 25-61, 1973. Disponível em: <http:// scholar.harvard.edu/hckelman/publications/violence-without-moral-restraintreflections-dehumanization-victims-and-victim>. Acesso em: 30 ago. 2013.

LAFER, C. Parecer - o caso Ellwanger : anti-semitismo como crime da prática do racismo. Revista de informação legislativa, [S. 1.], v. 41, n. 162, p. 53-89, abr./jun. de 2004. Disponível em: <http://www2.senado.leg.br/bdsf/bitstream/ handle/id/948/R162-08.pdf?sequence=4>. Acesso em: 31 jul. 2013.

MOLINA, T. S. Relevância da dimensão cultural na escolarização de crianças negras. 2011. 153 f. Dissertação (Mestrado)-Faculdade de Educação, Universidade de São Paulo, São Paulo, 2011. Disponível em: <http://www. teses.usp.br/teses/disponiveis/48/48134/tde-04072011-153413/>. Acesso em: 21 ago. 2013.

MUNDURUKU, D. O caráter educativo do movimento indígena brasileiro (1970-1990). São Paulo: Paulinas, 2012.

PEREIRA, J. H.V. Educação e fronteira: processos indenitários de migrantes de diferentes etnias. 2002. 150 f. Tese (Doutorado)-Faculdade de Educação da Universidade de São Paulo, Universidade de São Paulo, São Paulo, 2002.

Recebido em: 23/09/2013

Aceito para publicação em: 24/10/2013

\section{Collective memory and insurgence against oblivion Abstract}

This article seeks to analyze how the amnesic abandon to which the Brazilian State and Society has relegated the collective memory could impact the school conviviality, by presenting a comparative study, based in bibliographical and documental survey. It searches to discuss the right to collective memory as a source of social transformation, particularly in school. Based in Habermas, discussion on the Memorial to the II World War and violent domination victims, in Berlin, it is presented themes about African-descendants' and indigenous 
peoples'discrimination, and Constitutional rights and guaranties as well. This article aims at to bringing subsidies sources, presenting contribution to the school everyday life, administration and public policies of education, to reflect about processes that have been marginalized in the social conscience and even so are so resistant, that return when and where one could less expect, as repressed contents. Keywords: Collective memory. Holocaust and education. National conscience. School conviviality.

\section{Memoria colectiva e insurgencia contra el olvido: a favor de la convivencia en la escuela Resumen}

Este artículo busca analizar cómo el amnésico abandono a que ha sido relegada la memoria colectiva por el Estado y por la sociedad brasileña puede afectar a la convivencia escolar, a través de un estudio comparativo, basado en levantamiento bibliográfico y documental. Busca discutir el derecho a la memoria como fuente de cambio social, especialmente en la escuela. Destaca las reflexiones de Habermas sobre el "Monumento a las víctimas de la guerra y la dominación violenta" en Berlín. Examina la discriminación a los indígenas y negros en Brasil y disposiciones constitucionales que deben repercutir en el hacer escolar y en las políticas públicas de la educación. Para ayudar en la definición de las políticas públicas de educación, busca sugerir fuentes de aportaciones, en la escuela y en la sociedad, para la reflexión sobre procesos importantes que han quedado al margen de la conciencia nacional y, sin embargo, resisten como contenidos reprimidos que vuelven cuando y donde menos se espera.

Palabras clave: Memoria colectiva. Conciencia nacional. Memoria y políticas públicas. Convivencia escolar. 